\title{
Mini-invasive technique for bone patellar tendon bone harvesting: its superiority in reducing anterior knee pain following ACL reconstruction
}

\author{
Philippe Beaufils • Fabrice Gaudot • Olivier Drain • \\ Philippe Boisrenoult • Nicolas Pujol
}

Published online: 8 April 2011

(C) Springer Science+Business Media, LLC 2011

\begin{abstract}
Arthroscopically-assisted ACL-reconstructions are currently reliable, reproducible. Residual anterior knee symptoms however, especially after patellar-BTB graft use, are not uncommon occurrences. Contributing factors are numerous and include injury to the saphenous nerve infrapatellar branches and/or histologic changes at the harvest site. The use of mini invasive harvesting technique decreases the risk of injury to the saphenous nerve infrapatellar branches while preserving the peritenon. The double-incision approach significantly reduces the mid-term incidence of anterior knee pain after ACL-reconstruction. Additionally, this technique markedly decreases the occurrence of sensory disorders and the extent of hypoesthesia. We thus advocate the use of a double-incision graft harvesting technique in ACLreconstruction using a patellar-bone-tendon-bone transplant.
\end{abstract}

Keywords Anterior cruciate ligament reconstruction - Bone tendon bone graft - Anterior knee pain - Saphenous nerve Mini invasive technique

\section{Introduction}

Current concepts of anterior cruciate ligament (ACL) reconstruction were originally described by Jones [1] in 1963 and gained widespread acceptance in the 1980s. These procedures have already reported satisfactory outcome regarding improvement of knee laxity.

P. Beaufils $(\bowtie) \cdot$ F. Gaudot $\cdot$ O. Drain $\cdot$ P. Boisrenoult $\cdot$ N. Pujol Department of Orthopaedics \& Traumatology, André Mignot Hospital Center,

177 , rue de Versailles,

78157, Le Chesnay, Cedex, France

e-mail: pbeaufils@ch-versailles.fr
However, despite successful results, anterior knee pain is a common occurrence after bone tendon bone (BTB) reconstruction and can interfere with patient satisfaction An incidence of 4 to $60 \%$ of anterior knee pain has been reported in the literature [2,3]. Depending on pain severity, this condition might be either considered as a complication or a normal postoperative outcome. Moreover, dysesthesia, kneeling difficulties have been also reported

Anterior knee pain may have a large variety of causes, two of them being specifically related to bone-patellar tendon-bone graft techniques: injury to the infrapatellar branches of the saphenous nerve (IBSN) and inflammatory response related to the donor site healing process (tendinopathy).

Therefore, other graft choices have been used to reduce the donor site morbidity associated with patellar tendon grafts [4, 5 and 6], even if it has not dramatically decreased the incidence of pain or discomfort. However, due to its widely accepted advantages (high mechanical strength, reliable fixation), the patellar tendon graft remains a very popular option in ACL reconstruction.

Several technical improvements have been proposed to decrease the morbidity of BTB harvesting. Berg [7] and Liu [8] propose to suture the peritenon and to fill (as we do) the bone harvesting sites. But according to Kartus [9] and Brandsson [10], these proposals do not diminish the rate of post op anterior knee pain.

In order to prevent IBSN while preserving the peritenon, which improves the tendon healing process, mini invasive techniques have been proposed [11••, 12-14], which allow to harvest the bone patellar tendon bone graft without tearing peritenon, and the majority of neural branches. All these authors propose a double incision (vertical or horizontal) 


\section{Anatomy}

Many anatomic studies have evaluated the course of the saphenous nerve in the anterior knee region [15-20]. In our own anatomical study $[13,15]$ on 18 cadaver knees, we harvested BTB graft using double incision technique and then exposed the anterior aspect of the knee in order to assess the anatomy of the saphenous branches and the eventual injuries of these branches

We found the following results:

- there were 2 branches in 12 cases (Fig. 1a) and 3 branches in 6 cases (Fig. 1b)

- the mean distance between the tip of the patella and the proximal branch was $21.9 \mathrm{~mm}(15-30 \mathrm{~mm})$

- the mean distance between the more distal branch and the top of the anterior tibial tubercle was $16.2 \mathrm{~mm}(0-27 \mathrm{~mm})$.

- All the branches were located between the distal part of the proximal incision and the proximal part of the distal incision.

- In 15 cases there were no neural tear. In 2 cases, distal branch was torn. In 1 case proximal branch was torn through the antero medial arthroscopic portal (Fig. 1b) [20]

- Among a total of 42 branches, only 3 were torn. Distal branch is at risk

- Peritenon was always preserved (Fig. 1a)

- BTB graft was always consistent

This technique is technically feasible and preserves peritenon and neural branches

\section{Operative technique}

Patient positioning is as usual. Graft harvest is carried out with the knee placed in $90^{\circ}$ of flexion. Two vertical incisions, twenty millimetres in length, are made (Fig. 2). The proximal incision doesn't go below the tip of the patella while the distal incision is centred on the anterior tibial tubercle [13, 14]. Tsuda et al. [12] advocate the use of horizontal incisions and dissection of retaniculum. Horizontal incisions would decrease the risk of potential injury to neurologic structures and provide improved surgical access to the tendon width and tibial tunnel. According to Mishra et al. [21], horizontal incisions would also result in a more satisfactory cosmetic appearance. Tsuda [12] and Mishra [21] do not report any wound complication. However, just like Kartus et al. [11••], we advocate the use of a vertical incision to facilitate its re-use in case of later surgery.

Subcutaneous tissue is incised on the patella and ATT. Metzenbaum scissors are passed subcutaneously from the proximal to the distal incision between the peritenon and the anterior aspect of the patellar tendon. The mid third of the tendon is then dissected, using either a specific double bladed stripper ( $9 \mathrm{~mm}$ for female or $11 \mathrm{~mm}$ for male) or simply a Ethibond suture which acts from proximal to distal as a Gigli saw through the tendon. The patellar tendon fibres are split longitudinally from the patella to the anterior tibial tubercle insertion. A $20 \mathrm{~mm} \times 10 \mathrm{~mm}$ patellar bone block, interdependent from the patellar tendon, is then harvested using an oscillating saw blade (Fig. 2b). Patellar graft is released from Hoffa's ligament using Metzenbaum scissors which are introduced in the proximal incision. A Kelly forceps is
Fig. 1 Cadaver study. a Left knee; example of two infra patellar branches. Mini invasive technique allows to preserve infra patellar saphenous branches and peritenon. b Left knee : example of three infrapatellar saphenous branches. The proximal branch is at risk through the arthroscopic infra medial portal. The distal branch which runs just at the top of the ATT, is at risk through the distal approach. (From Drain, et al. [13]; with permission from Elsevier)
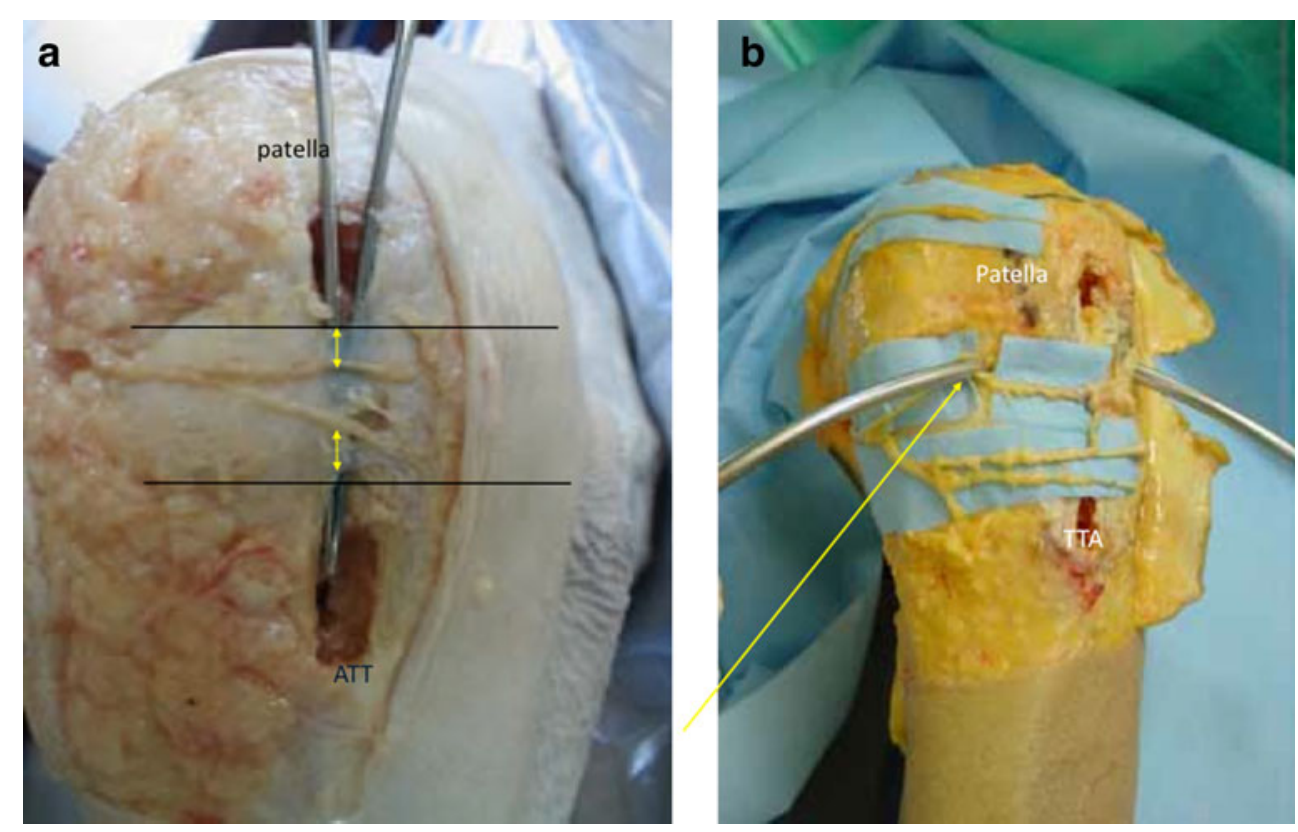
Fig. 2 A two-incision graft harlandmarks are drawn on the skin. b The patellar bone plug, armed with a thread, is harvested. $\mathbf{c}$ The peritenon layer is separated from the patellar tendon. The patellar bone plug is held with Kelly forceps. d The patellar bone plug and mid-third of the patellar tendon are drawn towards the tibial incision. The tibial bone plug is then harvested. e Arthroscopy is then performed via standard approaches vesting approach. a The incision
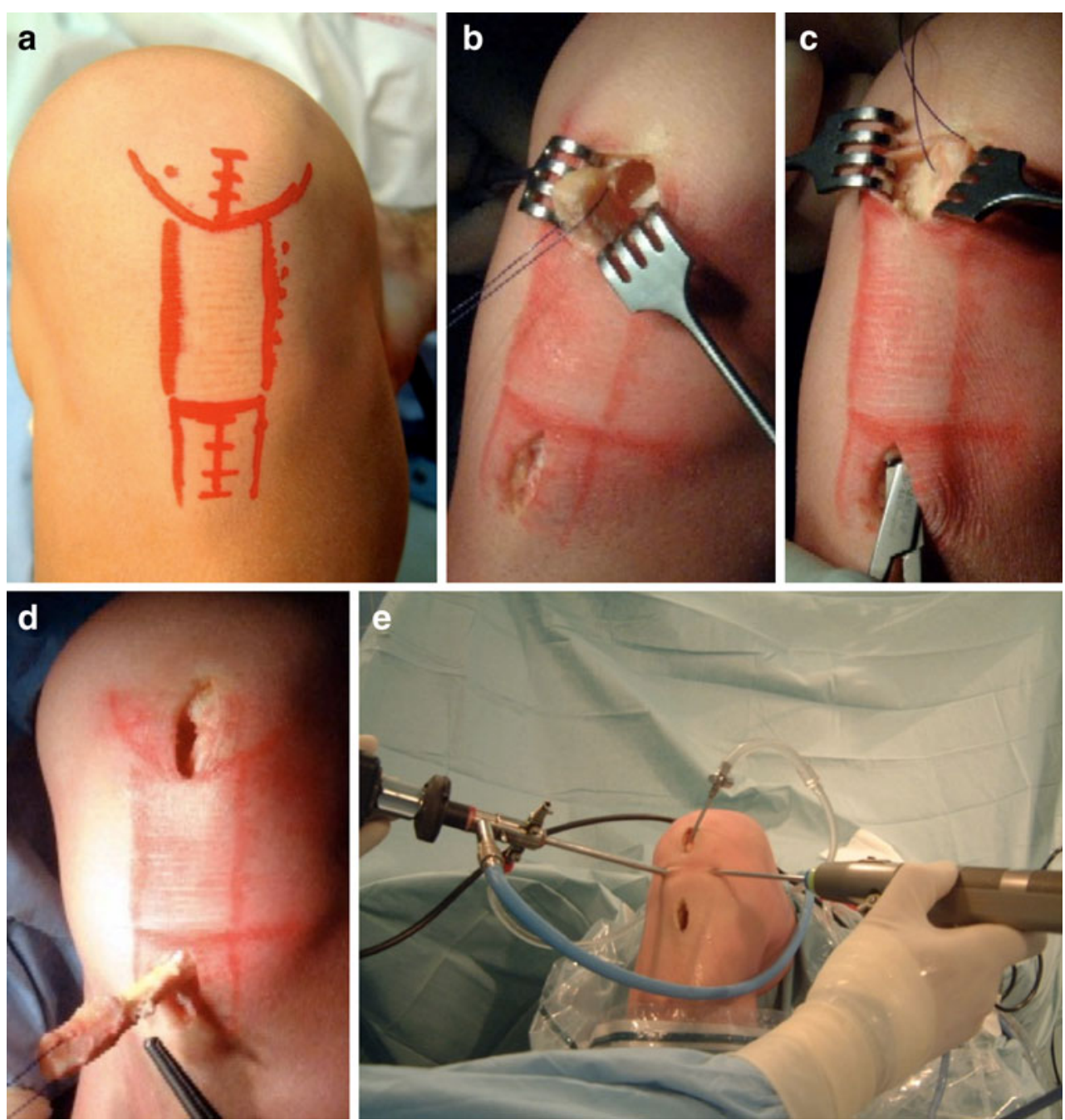

passed between tendon and peritenon from tibial to patellar incision allowing extraction of the patellar bone block through the tibial incision (Fig. 2c). The oscillating saw is then used to cut a $20 \mathrm{~mm}$ long tibial bone block (Fig. 2d). The bone-tendon-bone graft is thus harvested via this double-incision approach. The standard infero-medial and infero-lateral arthroscopy-assisted approaches are carried out (Fig. 2e). It is possible to create the inferolateral approach through the proximal incision. For the infero medial approach, we use an horizontal incision to minimize the risk of nerve damage. Both tunnels are created independently. The tibial tunnel is created through the distal incision. The femoral tunnel is created via the infero medial portal.

\section{Results}

Goals of this technique are:

- to diminish post op anterior knee pain

- to diminish hypoesthesia and dysesthesia
- to improve ability to kneel (kneeling test or kneewalking test)

\section{Standard incision BTB reconstruction versus Hamstrings reconstruction}

In the Frnch Arthroscopy Society (SFA) retrospective series (136 BTB and 122 hamstrings with a minimum follow up of 18 months) reported by Gaudot [6] and specifically devoted to anterior knee pain (AKP), AKP is more frequent in the standard harvested BTB group (33\%) than in the hamstring group (25\%), but the difference is not significant. This absence of difference is also reported by Eriksson et al. who studied randomly 84 BTB and 83 hamstrings [4].

Patello femoral score is $<90$ in both groups in the SFA's study. Subjective IKDC score is better in the BTB group ( $p=$ $0.04)$. The level of pain is statistically less in the BTB group $(p=0.04)$ where the location of pain strictly corresponds to the tip of the patella and the patellar tendon. In the hamstring group, it is located more medially. 
Ability to kneel is much more difficult in the BTB group than in the hamstring group [4-6]

Hypoesthesia is more important after BTB reconstruction than hamstring reconstruction $(p<0.0001)$

\section{Standard BTB versus mini invasive BTB harvesting}

We reported a prospective comparative study, of 19 single standard incision technique and 21 double incision mini invasive technique (mean follow up: 32,7 months). Both groups were comparable in terms of age, time to surgery, pre op status, etc....

The clinical diagnosis of AKP was based on patient's positive response to the question: "Is your anterior knee painful?" Pain severity was not interpreted by the examiner. In all cases, pain and subjective hypoesthesia items were recorded prior to knowing whether single or doubleincision approach had been performed.

The examination form included:

- Pain-related items (cause of trauma, type of surgical approach, associated procedures, postoperative analgesia, postoperative patient's satisfaction, immediate complication, algodystrophy).

- At last follow-up: Pain assessment (anterior knee pain and/or other pain, severity, evolution, pain location, Lille patello-femoral rating system [22], objective specific tests; analysis of sensorial disturbances (localization, type, extent on mapping), functional assessment (IKDC), quality of life assessment (SF36), radiographic and sonographic investigations.

A transparent overlay featuring a centimetric grid (Fig. 3) was placed over the knee to determine the area of sensory disorder; scars were transferred and area of the sensory disorder was drawn. The results according to each group are shown in Table 1.

The double-incision sub-group showed a significant decrease in pain frequency but not in pain severity when compared with the single-incision sub-group $(19 \%$ versus $58 \% ; p=0.01)$. the global rate of pain was $37.5 \%$ which strongly corroborates the findings of previous studies [23-26] incidence of sensory disorders was lower $(p=0.002)$ while involving a smaller surface area (4.9 $\mathrm{cm} 2$ vs $11.5 \mathrm{~cm} 2 ; p<0.03)$. The knee-walking test was significantly better in the double-incision subgroup $(p<0.02)$. No significant differences could be detected from the results of the patello-femoral, IKDC subjective and objective scores. SF36 scores were analyzed either by comparing both group results or by comparing the whole series data with French normal ranges according to age and gender. No significant differences were observed.

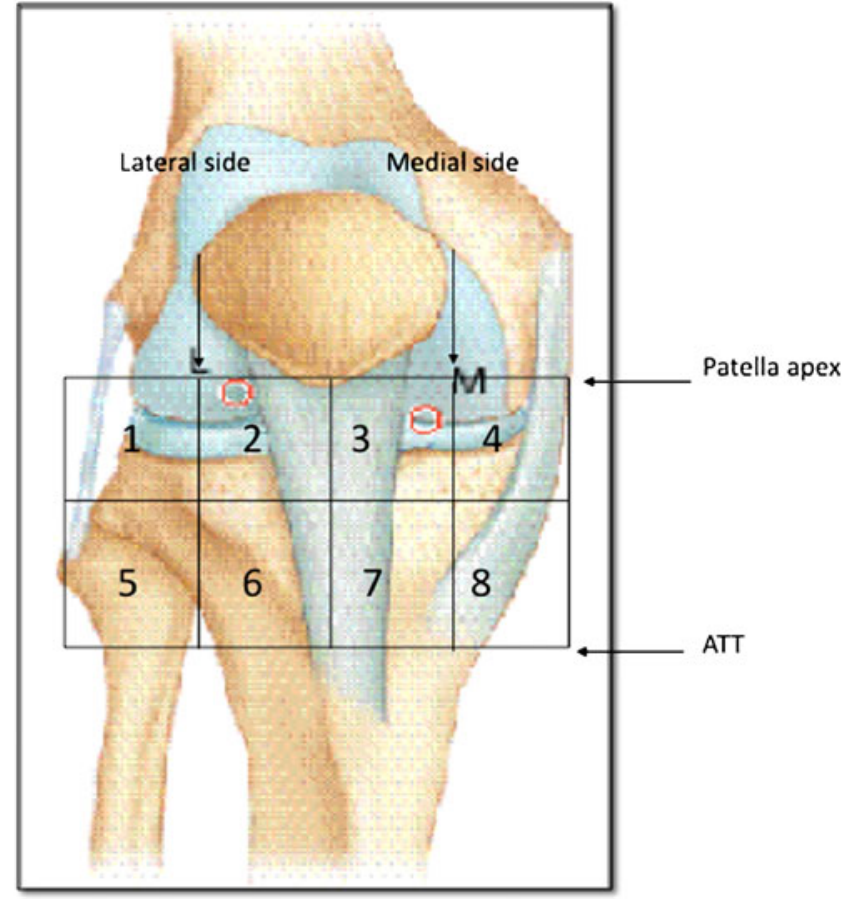

Fig. 3 A transparent overlay featuring a $\mathrm{cm}$ grid is placed on the knee to measure the are of hypoesthesia. (From Gaudot, et al. [14••]; with permission from Elsevier)

No statistically significant correlation between occurrence of anterior knee pain and presence of sensorial disturbance was detected $(p=0.39)$. Furthermore, there was poor correlation between anterior knee pain and extent of sensorial disturbance $(p=0.52)$. However, relationship between kneewalking test results and extent of hypoesthesia could be established. The surface area of hypoesthesia had an average of $10.34 \mathrm{~cm} 2$ in patients with abnormal test results and $3.78 \mathrm{~cm} 2$ in those with normal test results $(p=0.035)$.

Patellar height was identical in both groups reporting a Caton and Deschamps index [27] of 0.99 for the doubleincision sub-group (range 0.68 to 1.30 ) and 0.99 for the single-incision sub-group (range 0.81 to 1.29 ).

Seventeen patients (10 double-incisions and 7 singleincisions) were assessed ultrasonographically at a mean follow-up of 28 months (range 22 to 32) (Table 2). The patellar tendon donor site defect was significantly thicker than the contralateral one $(p<0.0001)$. Mean tendon thickness value was compared according to the surgical approach and the pain-free or painful status of patients. Tendon thickening was less obvious in the double-incision sub-group although ultrasonographic measurements failed to show a statistically significant difference between the two groups. We searched for correlation between anterior knee pain and tendon thickening value:

- nine pain-free patients had a mean thickening value of $0.193 \mathrm{~cm} 2$; 
Table 1 Results according to the approach

\begin{tabular}{|c|c|c|c|c|}
\hline & & Single-incision $(n=19)$ & Double-incision $(n=21)$ & Level of significance $(p)$ \\
\hline Anterior knee pain & & $58 \%$ & $19 \%$ & $p=0.01$ \\
\hline Pain severity (range $0-10$ ) & & $1.9 / 10$ & $2.4 / 10$ & NS \\
\hline \multirow[t]{3}{*}{ Pain location } & Patella & 5 & 1 & \multirow[t]{3}{*}{ NS } \\
\hline & Tendon & 4 & 2 & \\
\hline & Anterior tibial tubercle & 2 & 1 & \\
\hline Hypoesthesia & & 17 & 9 & $p=0.002$ \\
\hline Hypoesthesia surface area $(\mathrm{cm} 2)$ & & 11.5 & 4.9 & $p<0.03$ \\
\hline \multirow[t]{3}{*}{ Knee-walking test } & Normal & 3 & 11 & \multirow[t]{3}{*}{$p<0.02$} \\
\hline & Unpleasant & 13 & 8 & \\
\hline & Difficult & 3 & 2 & \\
\hline \multirow[t]{4}{*}{ Kneeling } & No difficulty & 3 & 8 & \multirow[t]{4}{*}{$p=0.24 \mathrm{NS}$} \\
\hline & Mild difficulty & 11 & 8 & \\
\hline & Moderate diff. & 2 & 3 & \\
\hline & Severe difficulty & 3 & 2 & \\
\hline \multirow[t]{3}{*}{ Squatting } & Possible painlessly & 15 & 17 & \multirow[t]{3}{*}{$p=0.26 \mathrm{NS}$} \\
\hline & Possible but painful & 4 & 2 & \\
\hline & Impossible & 0 & 2 & \\
\hline Patello-femoral score & & 90.8 & $91 / 100$ & NS \\
\hline Weighted IKDC subjective score & & $84 / 100$ & $85 / 100$ & NS \\
\hline \multirow[t]{4}{*}{ Objective IKDC } & A & 9 & 8 & \multirow[t]{4}{*}{ NS } \\
\hline & $\mathrm{B}$ & 9 & 9 & \\
\hline & $\mathrm{C}$ & 1 & 3 & \\
\hline & $\mathrm{D}$ & 0 & 1 & \\
\hline
\end{tabular}

(From Gaudot, et al. [14••]; with permission from Elsevier)

- eight painful patients had a mean thickening value of $0.390 \mathrm{~cm} 2$.

We did not consider this difference as being significant $(p=0.08)$.

In our series, AKP incidence is thus lower in the doubleincision sub-group (19\%) than in the single-incision subgroup $(58 \%)(p=0.01)$. Kartus et al. [11••] do not demonstrate any relationship. However, he uses different parameters for evaluation of AKP. (combination of the three following items: anterior knee pain with the knee flexed $90^{\circ}+$ pain during stair climbing + pain during physical effort). Paradoxically, he reports an incidence of pain of $34 \%$ with the mini-invasive approach and $20 \%$ in the control group (non significant). Tsuda et al. [12] report a series of 75 patients subjected to a double-incision approach (follow up 35-month - no control group). AKP incidence is $17 \%$ which corroborates our results in the double-incision group.

In our series, we observe a significant difference between normal and abnormal knee-walking test in favour of the double-incision approach. Kartus et al. [11••] do not establish such correlation $(p=0.07)$.

We do not observe any direct relationship between location of hypoesthesia and anterior knee pain, either from a qualitative or quantitative point of view, which contradicts Kartus et al's. observations [11••] and French Arthroscopic Societie's symposium [6] but corroborates Tsuda et al.'s findings [12]. However, extent of hypoesthesia and knee-walking test are correlated. Injury to the infrapatellar

Table 2 Sonographic results according to the approach

\begin{tabular}{|c|c|c|c|c|}
\hline & Single incision $n=7$ & Double incision $n=10$ & $n=17$ & Comparison single/double (p) \\
\hline Surface area of donor site defect $(\mathrm{cm} 2)$ & 0.880 & 0.720 & $0.786(0.440-1.34)$ & 0.2 \\
\hline $\begin{array}{l}\text { Surface area of contralateral tendon } \\
(\text { control })(\mathrm{cm} 2)\end{array}$ & 0.547 & 0.467 & $0.500(0.210-0.850)$ & 0.38 \\
\hline Delta (donor site - control site) $(\mathrm{cm} 2)$ & 0.333 & 0.253 & $0.286(0.40-0.840)$ & 0.50 \\
\hline
\end{tabular}


branches of the saphenous nerve is likely to induce functional impairment which reinforces interest in nerve preservation.

The double-incision approach significantly decreases the risk of anterior knee pain which is partly attributed to the preservation of the infrapatellar branches $[11 \bullet \bullet]$. However, the lack of difference between the patellofemoral scores and the absence of correlation with the area of hypoesthesia suggest that pain is not only related to nerve injury. Pain might also be attributed to the tendon itself. Peritenon protection through the double-incision approach appears to contribute to the tendon trophicity preservation.

Therefore, the double-incision approach preserves transplant quality and does not induce greater morbidity than the conventional method [5].

Ultrasonography has proved to be effective and reliable in the measurement of patellar tendon thickness [28]. Tendon thickening after graft harvest is documented by Berg et al. [29] and Wiley et al. [30]. Our series is the first one to compare the effect of two graft harvesting techniques on tendon thickening. Jarvela et al. [31] reviewed 31 patients at a mean follow-up of 10 years after reconstruction. Patellar tendon thickness was measured sonographically at its proximal and distal third. Patients with anterior knee pain reported greater tendon thickness than pain-free patients $(5.6 \mathrm{~mm}$ versus $5 \mathrm{~mm}$, the mean thickness of the healthy contralateral tendon was $4.2 \mathrm{~mm}$ ). In our series, the coronal section was used for measurement of the midportion of the tendon via a computerised method. Although our results corroborate Jarvela's findings, it does not appear significant enough.

\section{Conclusion}

Double-incision approach reduces the mid-term incidence of anterior knee pain as well as the incidence and surface area of hypoesthesia. Preservation of the infrapatellar branches of the saphenous nerve and better tendon trophicity through preservation of peritenon thus provide strong evidence for efficiency and reliability of the doubleincision approach.

Furthermore, the double-incision approach does not compromise the quality of reconstruction.

We advocate the use of a double-incision graft harvesting approach in bone-patellar tendon-bone ligament reconstruction. This approach is routinely performed in our department.

Disclosure No potential conflicts of interest relevant to this article were reported.

\section{References}

Papers of particular interest, published recently, have been highlighted as:

•- Of major importance

1. Jones KG. Reconstruction of the anterior cruciate ligament using the central one-third of the patellar ligament. J Bone Joint Surg Am. 1970;52:838-9.

2. Plancher KD, Steadman JR, Briggs KK, Hutton KS. Reconstruction of the anterior cruciate ligament in patients who are at least forty years old. A long-term follow-up and outcome study. J Bone Joint Surg Am. 1998;80:184-97.

3. Shaieb MD, Kan DM, Chang SK, Marumoto JM, Richardson AB. A prospective randomized comparison of patellar tendon versus semitendinosus and gracilis tendon autografts for anterior cruciate ligament reconstruction. Am J Sports Med. 2002;30:214-20.

4. Eriksson K, Anderberg P, Hamberg P, Olerud P, Wredmark T. There are differences in early morbidity after ACL reconstruction when comparing patellar tendon and semi-tendinous tendon graft. Scand J Med Sports. 2001;11:170-7.

5. Aune A, Holm I, Risberg M, Jensen H, Steen H. Four-strand hamstring tendon autograft compared with patellar tendon-bone autograft for anterior cruciate ligament reconstruction. Am J Sports Med. 2001;29:722-8.

6. Gaudot F, Chalencon F, Nourissat G, Dejour D, Potel JF, Frischty D, Beaufils $\mathrm{P}$ and the French Arthroscopy Society Impact of anterior knee pain on mid term outcome after anterior cruciate ligament reconstruction. Rev Chir Orthop 2008, 94 suppl 8, S372-375

7. Berg P, Mjoberg B. A lateral skin incision reduces peripatellar dysaesthesia after knee surgery. J Bone Joint Surg Br. 1991;73:3746.

8. Liu SH, Hang DW, Gentili A, Finerman GA. MRI and morphology of the insertion of the patellar tendon after graft harvesting. J Bone Joint Surg Br. 1996;78:823-6.

9. Kartus J, Movin T, Karlsson J. Donor-site morbidity and anterior knee problems after anterior cruciate ligament reconstruction using autografts. Arthroscopy. 2001;17:971-80.

10. Brandsson S, Faxen E, Eriksson BI, Kalebo P, Sward L, Lundin $\mathrm{O}$, et al. Closing patellar tendon defects after anterior cruciate ligament reconstruction: absence of any benefit. Knee Surg Sports Traumatol Arthrosc. 1998;6:82-7.

11. •- Kartus J, Ejerhed L, Sernert N, Brandsson S, Karlsson J, Comparison of traditional and subcutaneous patellar tendon harvest. A prospective study of donor site-related problems after anterior cruciate ligament reconstruction using different graft harvesting techniques, Am J Sports Med 2000, 28, 328-335. Authors demonstrate in this comparative study a correlation between the surface of hypoesthesia and the rate of Anterior Knee pain. They conclude tears of the infra patellar branches due to anterior approach are a major cause of anterior knee pain after BTP reconstruction.

12. Tsuda E, Okamura Y, Ishibashi Y, Otsuka H, Toh S. Techniques for reducing anterior knee symptoms after anterior cruciate ligament reconstruction using a bone-patellar tendon-bone autograft. Am J Sports Med. 2001;29:450-6.

13. Drain O, Beaufils P, Thevenin Lemoine C, Boggione C, Katabi M, Charrois O. Mini invasive double incision for patellar tendon harvesting in anterior cruciate ligament reconstruction. Rev Chir Orthop. 2007;93:836-41.

14. •- Gaudot F, Leymarie JB, Drain O, Boisrenoult P, Charrois O, Beaufils $\mathrm{P}$ Double-incision mini-invasive technique for BTB Harvesting: Its superiority in reducing anterior knee pain 
following ACL reconstruction Orthop Traumat Surg Res 2009 95, 28-35. The authors do not demonstrate a direct relationship between anterior knee pain and dysesthesia, but a relationship between dysesthesia and knee walking test. These results suggest that decrease of AKP with mini invasive technique is not only related with preservation of infrapatellar branches, but also with preservation of the peritenon.

15. Thevenin-Lemoine C, Boggione C, Gagey O, Beaufils P, Préservation des rameaux infrapatellaires du nerf saphène pour un mini abord lors des ligamentoplasties du genou de type os-tendon-os. Étude cadavérique, Rev Chir Orthop 2004, 90 (Suppl. 1), 187.

16. Arthornthurasook A, Gaew-Im K, Study of the infrapatellar nerve, Am J Sports Med 1988, 57-59.

17. Ebraheim NA, Mekhail AO. The infrapatellar branch of the saphenous nerve: an anatomic study. J Orthop Trauma. 1997;11:195-9.

18. Kartus J, Ejerhed JL, Eriksson BI, Karlsson J. The localization of the infrapatellar nerves in the anterior knee region with special emphasis on central third patellar tendon harvest: a dissection study on cadaver and amputated specimens. Arthroscopy. 1999;15:577-86.

19. Bonin N. Rapports entre nerf infra-patellaire et ligament patellaire: étude anatomique et application au prélèvement du greffon os-ligament patellaire-os. Rev Chir Orthop. 2006;92:161-2.

20. Tifford CD. The relationship of the infrapatellar branches of the saphenous nerve to arthroscopy portals and incisions for anterior cruciate ligament surgery. An anatomic study. Am J Sports Med. 2000;28:562-7.

21. Mishra AK, Fanton GS, Dillinham MF, Carver TJ. Patellar tendon graft harvesting using horizontal incisions for anterior cruciate ligament reconstruction. Arthroscopy. 1995;11:749-52.

22. Remy F, Besson A, Gougeon F, Migaud H, Duquenoy A. Évaluation fonctionnelle de l'instabilité fémoro-patellaire par un score sur 100 points. Rev Chir Orthop. 1999;85 Suppl 3:92-3.
23. Otto D, Pinczewski LA, Clingeleffer A, Odell R. Five-year results of single-incision arthroscopic anterior cruciate ligament reconstruction with patellar tendon autograft. Am J Sports Med. 1998;26:181-8.

24. Ejerhed L, Kartus J, Sernert N, Kohler K, Karlsson J. Patellar tendon or semitendinosus tendon autografts for anterior cruciate ligament reconstruction? A prospective randomized study with a two-year follow-up. Am J Sports Med. 2003;31:19-25.

25. Marder RA, Raskind JR, Carroll JM. Prospective evaluation of arthroscopically assisted anterior cruciate ligament reconstruction. Patellar tendon versus semitendinosus and gracilis tendons. Am J Sports Med. 1991;19:478-84.

26. Otero AL, Hutcheson L. A comparison of the doubled semitendinosus/gracilis and central third of the patellar tendon autografts in arthroscopic anterior cruciate ligament reconstruction. Arthroscopy. 1993;9:143-8.

27. Caton J, Deschamps G, Chambat P, Lerat JL, Dejour H. Les rotules basses: à propos de 128 observations. Rev Chir Orthop. $1982 ; 68: 317-25$.

28. Roberts CS, King DH, Goldsmith LJ. A statistical analysis of the accuracy of sonography of the patellar tendon. Arthroscopy. 1999;15:388-91.

29. Berg EE. Intrinsic healing of a patellar tendon donor site defect after anterior cruciate ligament reconstruction. Clin Orthop. 1992;278:160-3.

30. Wiley JP, Bray RC, Wiseman DA, Elliott PD, Ladly KO, Vale LA. Serial ultrasonographic imaging evaluation of the patellar tendon after harvesting its central one third for anterior cruciate ligament reconstruction. J Ultrasound Med. 1997;16:251-5.

31. Jarvela T, Paakkala T, Kannus P, Toivanen J, Jarvinen M. Ultrasonographic and power Doppler evaluation of the patellar tendon ten years after harvesting its central third for reconstruction of the anterior cruciate ligament: comparison of patients without or with anterior knee pain. Am J Sports Med. 2004;32:39-46. 